\title{
CONTEXTUALIZAÇÃO DO JOGO ANTITÉTICO NO DE CONIURATIONE CATILINAE
}

\author{
Míriam Barcellos Goettems
}

\begin{abstract}
RESUMO: In this essay, we present an analysis on how Sallust's antithetic thought is structured, on the sintagmatic level, in the monograph De Coniuratione Catilinae. We aim at showing that the descriptive portraits, letters, speeches and digressions that the author interpolates along the narrative and which bear the distinctive mark of sallustian texts (though such insertions were not original because they were a common procedure, since Herodotus, in classical historioghaphy) constitute a privileged space for the contextualization of the dualistic theoretical model. This model that spells out several opposition pairs is presented, in a paradigmatic way, in the prologue of the monograph.
\end{abstract}

PALAVRAS-CHAVE: Salústio, De Coniuratione Catilinae, antítese, antíteses de palavras, antíteses frásicas.

"Igitur de Catilinae coniuratione quam uerissume potero paucis absoluam." (De C.C. 4, 3. $)^{1}$

Com essas palavras Salústio anuncia, quase ao final do prólogo de sua monografia intitulada $D e$ Coniuratione Catilinae, aquele que será o tema central da obra: a conjuração de Catilina. Logo adiante diz o autor: "De cuius hominis moribus pauca prius explananda sunt quam initium narrandi faciam" 2 (De C.C. 4, 5).

Tais palavras são importantes porque, ao introduzirem um retrato de Catilina e não a narrativa propriamente dita de sua conspiração, sublinham um traço marcante do texto salustiano, traço esse de que o prólogo - que analisamos no ensaio Considerações Preliminares sobre o Jogo Antitético na Historiografia de Salústio $^{3}$ - constitui o primeiro exemplo: o caráter compósito desse texto, no qual a narrativa, em lugar de se processar de forma contínua, está entremeada de digressões, discursos, retratos e cartas.

Naturalmente sabemos que esse procedimento de Salústio não é original e que sua utilização remonta aos primórdios da historiografia grega: desde Heródoto e Tucídides as digressões e os discursos são partes importantes das obras históricas, sendo até digno de menção especial o fato de Políbio ter sido um dos poucos historiadores antigos a não inserir discursos em seus escritos (BESSELAAR, 1958, p.13).

Mas o que nos interessa neste momento não é o ineditismo do procedimento. O importante é nos darmos conta de sua função no contexto da obra. Segundo afirma José Riquelme Otálora, Salústio, ao deixar de lado a fria narração dos fatos, se vale da introdução dos elementos antes arrolados "para insertar en el decurso del relato sus ideas, interpretaciones y juicios de valor sobre la historia; relaciones de causalidad próxima y remota, condicionamientos de tipo social y moral, limitaciones impuestas por el carácter de los personajes, etc.” (OTÁLORA, 1978, p.297).

Do ponto de vista da questão básica de que nos estamos ocupando - o uso da antítese -, não é difícil verificar que os retratos, as cartas, os discursos e as digressões constituem, no eixo sintagmático da obra, o espaço privilegiado para a contextualização daquilo que, paradigmaticamente, o prólogo nos apresenta: o pensamento antitético de Salústio.

\footnotetext{
Míriam Barcellos Goettems é professora da UFRGS.

1 "Vou, pois, da maneira mais fiel que me for possível, fazer um relato sucinto da conjuração de Catilina." (Observação: As traduções que aqui apresentamos são de autoria do Prof. Antônio da Silveira Mendonça, que publicou, pela Editora Vozes (ver Bibliografia), a tradução completa das duas monografias salustianas. Com respeito ao texto latino, servimo-nos do estabelecido por Alfred Ernout e publicado pela Société d'Édition "Les Belles Lettres", que a Bibliografia indica.)

2 "Julgo oportuno fazer uma breve exposição sobre o caráter dessa pessoa, antes de iniciar a narração."

${ }^{3}$ Permitimo-nos incluir o ensaio citado na Bibliografia deste trabalho por julgarmos que a leitura dele pode não apenas servir para elucidar melhor algumas das questões aqui levantadas como ser significativa para os que se interessam mais profundamente pela questão do emprego da antítese por Salústio.
} 
Para que possamos dar o devido esclarecimento a essa idéia, houvemos por bem nos deter, de forma particular, na análise de alguns capítulos que julgamos exemplares em termos de interrupção do fluxo da narrativa, buscando verificar de que forma os pares opositivos estabelecidos - no ensaio antes referido - no estudo do prólogo, se configuram no decorrer da obra.

Selecionamos como foco inicial de nossa investigação o capítulo 5, ou seja, o retrato de Catilina, partindo do estudo do par antitético animus x corpus.

Esses dois elementos, em sua primeira aparição no pólo sintagmático, estão estreitamente vinculados: "Lucius Catilina, nobili genere natus, fuit magna ui et animi et corporis [...]", (De C.C. 5, $1)$.

É óbvio que, mesmo no pólo paradigmático, esses dois elementos não estão totalmente separados: como afirma Salústio no capítulo 1, "nostra omnis uis in animo et corpore sita est" ${ }^{\circ}$ (De C.C. 1, 2), ou seja, em todos nós, mortais, dá-se a coexistência dos dois elementos; se assim não fosse, inexistiria o par antitético homines x cetera animalia, já que é o animus o elemento diferenciador entre os elementos constituintes de tal par. Eis o que diz, a esse respeito, Earl: "[...] in contrast to the other animals our power lies not only in our bodies but also in our minds, which are the ruling factors and which unite us to the gods, whereas the body is common to us and the brutes [...]" (EARL, 1961, p.7).

No entanto, mesmo que o animus seja "the ruling principle in human life" (EARL, 1961, p.7), há, segundo diz Salústio ainda no prólogo, homens "dediti uentri atque somno, indocti incultique", para os quais "contra naturam corpus uoluptati, anima oneri fuit" (De C.C. 2, 8). Ou seja, abre-se, já no prólogo, a possibilidade de existência de homens-só-corpo, cuja vida, idêntica à dos animais, não se distingue da morte. Sobre ambas - vida e morte - recai silêncio igual.

Catilina, no entanto, não pertence a tal grupo. A uma magna uis corporis ("Corpus patiens inediae, algoris, uigiliae, supra quam cuiquam credibile est." ${ }^{\prime \prime}$ - De C.C. 5, 3) aliava ele uma não menor uis animi, que o fez sobrepujar os demais e contribuiu para que ele se tornasse o líder de um egregium facinus (expressão aqui empregada no seu sentido mais literal, ou seja, de feito que se destaca entre os demais) e para que, por conseguinte, não passasse sua vida na obscuridade dos homens-só-corpo.

Mas, se isso é verdade, por que não podemos ver em Catilina um exemplo de uirtus? Para tentarmos responder a essa questão, reportamo-nos, inicialmente, ao conceito de uirtus que, segundo Earl, Salústio defende em sua obra: "the functioning of ingenium to achieve egregia facinora and thus to win gloria by the exercise of bonae artes" (EARL, 1961, p.16).

Baseando-nos nesse conceito, retornamos à análise do capítulo 5 da monografia, em cujo período inicial julgamos estar a primeira pista para a elucidação do porquê de Catilina não poder ser considerado um modelo de uirtus, ao se afirmar ser ele "ingenio malo prauoque"9 (De C.C. 5, 1).

Para sabermos exatamente o que é o ingenium, recorremos mais uma vez a Earl: "The individual rational intellect, differing from man to man and capable of improvement or debasement, is ingenium". Logo a seguir, diz esse mesmo crítico: "Ingenium is the natural talent, good or bad, of the animus which distinguishes men from the brutes" (EARL, 1961, p.10).

Tais definições impõem, necessariamente, uma nova pergunta: se o ingenium, que pode ser bom ou mau, faz parte do animus, como explicar que, no nível paradigmático ${ }^{10}$, tanto um quanto o outro tenham sido colocados na coluna 1 das oposições, ou seja, naquela à qual se afirmou pertencerem os elementos superiores dentro do dualismo metafísico?

A resposta parece-nos óbvia: o sintagma desmente o maniqueísmo do paradigma, cujo exame nos faz pensar que todos os componentes da coluna 1 sejam integralmente bons, em oposição aos da coluna 2, integralmente maus. O sintagma mostra-nos que, em ambas as colunas, existem elementos dotados, simultaneamente, de boas e de más características. Não foi o que demonstramos um pouco atrás, com relação a um componente da coluna 2, ao referirmos a magna uis corporis de Catilina? $\mathrm{O}$ corpo não é, por si só, necessariamente mau. O uso que fazemos dele é que lhe pode conferir essa característica - constatação que, todavia, não invalida o fato de que, em comparação com o animus, ele é

\footnotetext{
4 "Lúcio Catilina, oriundo de família nobre, era de grande vigor físico e intelectual [...]."

5 " $[. .$.$] toda nossa força depende da alma e do corpo."$

6 "[...] entregues ao ventre e ao sono, ignorantes e abrutalhados [...]."

7 "[...] contrariando a natureza, o corpo lhes foi fonte de prazer, a alma lhes foi um fardo."

8 "Seu corpo suportava a fome, o frio, as vigílias bem além do que qualquer pessoa possa acreditar."

9 "[...] de índole má e depravada."

${ }^{10}$ Nesse nível, enquanto animus se opõe a corpus, ingenium se opõe a uis (corporis), sendo tais oposições feitas de acordo com o dualismo metafísico, desenvolvido por Platão, em que os primeiros elementos de cada par antitético - no caso, animus e ingenium - são considerados superiores (membros da "Coluna 1" no ensaio Considerações Preliminares sobre o Jogo Antitético na Historiografia de Salústio), em detrimento dos segundos - no caso, corpus e uis (corporis) (membros da "Coluna 2").
} 
inferior. Da mesma forma, o ingenium não é, em si mesmo, necessariamente bom; ele está, por certo, em situação de vantagem com relação à uis corporis na busca que o ser humano faz da gloria, mas nem por isso pode deixar de haver equívoco em sua utilização no decorrer dessa busca.

Ora, se o ingenium pode não ser bom, o mesmo acontece com o animus, de que aquele é parte. É interessante verificarmos, a esse respeito, o modo como Salústio caracteriza, no capítulo 5, o animus de Catilina, cujo ingenium, segundo frisamos, é qualificado de malum e de prauum. Eis o que diz o historiador: "Animus audax, subdolus, uarius, cuius rei lubet simulator ac dissimulator; alieni adpetens, sui profusus; ardens in cupiditatibus; satis eloquentiae, sapientiae parum. Vastus animus inmoderata, incredibilia, nimis alta semper cupiebat"11 (De C.C. 5, 4-5).

Essas palavras de Salústio são imediatamente seguidas por outros dados de caráter biográfico, cuja citação vale a pena fazer, tendo em vista que eles nos fornecem a segunda grande pista para compreendermos o porquê de não ser Catilina um exemplo de uir uirtutis: "Hunc [Catilinam] post dominationem L. Sullae lubido maxuma inuaserat rei publicae capiundae, neque id quibus modis adsequeretur, dum sibi regnum pararet, quicquam pensi habebat"12 (De C.C. 5, 6).

Destacam-se nessa passagem, de modo particular, dois dados: o primeiro deles, o desejo desenfreado de Catilina de apoderar-se da república; o segundo, o fato de a ele não importarem os meios, desde que seu desejo pudesse ser satisfeito. Examinemos cada um desses dados individualmente.

Com respeito ao primeiro deles, cabe observar que o desejo de mando, sintagmaticamente expresso aqui através da figura de Catilina, já foi por nós examinado, em termos paradigmáticos, ao mostrarmos, em nosso trabalho anterior, que, no capítulo 2, Salústio destaca o caráter degenerativo da história, ao contrapor a uma época em que os homens viviam sem ambições, satisfeitos com o que possuíam (De C.C. 2, 1), outra, posterior, em que o desejo de dominar passou a ser motivo de guerras entre os povos (De C.C. 2, 2). Por outro lado, no mesmo capítulo 2, opõe o historiador a idéia de lubido (ali sem objeto definido) à de continentia (De C.C. 2, 5). Em ambas as situações, lubido pertence à coluna 2 dos pólos opositivos - a dos elementos inferiores. No entanto, como já vimos em relação a ingenium e animus, no plano sintagmático as características de cada elemento não se apresentam de forma tão estanque quanto no paradigmático, e - nesse caso ao contrário do que ocorre com ingenium e animus - nem tudo é mau na lubido dominandi. Para comprová-lo, basta ver o que diz Salústio acerca da ambitio, termo que consideramos equivalente, no vocabulário salustiano, à expressão em foco: "Sed primo magis ambitio quam auaritia animos hominum exercebat, quod tamem uitium propius uirtutem erat. Nam gloriam, honorem, imperium bonus et ignauos aeque sibi exoptant; sed ille uera uia nititur, huic, quia bonae artes desunt, dolis atque fallaciis contendit"13 (De C.C. 11, 1-2).

Essas palavras finais fazem-nos retornar ao segundo dos dados destacados em De C.C. 5, 6 - o fato de Catilina não se importar com os meios através dos quais chegaria ao poder, desde que isso pudesse ser concretizado -, bem como à definição de uirtus apresentada anteriormente ${ }^{14}$, a qual se encerra com a idéia de que só se alcança gloria através de bonae artes. Ao desconhecer a uera uia para concretizar sua ambitio - a priori um desejo legítimo, tanto para o bonus quanto para o ignauus -, Catilina, mesmo tendo posto a funcionar sua magna uis animi para a execução de um egregium facinus, não pode ser considerado um modelo de uirtus.

O fato de Catilina servir-se dolis atque fallaciis e não uera uia - ou seja, as bonae artes - para tentar a consecução de sua ambitio fica bem patente nos capítulos 34 e 35, através dos quais tomamos conhecimento do conteúdo de cartas que teriam sido mandadas por ele a consulares e a outros cidadãos importantes de Roma (De C.C. 34) e do teor de uma correspondência dirigida, no mesmo período, a Q. Catulo (De C.C. 35).

Reforçando nossa tese de que passagens como os retratos, as digressões, os discursos e as cartas constituem o espaço privilegiado para a análise, em termos sintagmáticos, das antíteses referidas no proêmio da monografia, vamos encontrar, no confronto entre o conteúdo dos dois tipos de

\footnotetext{
11 "Espírito atirado, astuto, versátil, capaz de tudo fingir e dissimular, ávido dos bens alheios, pródigo dos seus, fogoso nas paixões; de muita eloquiência, de pouca sabedoria. Espírito desmesurado, estava sempre a ambicionar coisas sem limites, as fantásticas, as altas demais."

12 "Depois da ditadura de Sila, dele se apossou o desejo desenfreado de se apoderar da república. Pouco se lhe dava com que meios a isso chegaria, contanto que conquistasse o reino."

13 "No entanto, a princípio a ambição, mais do que a ganância, acossava as almas das pessoas, vício, porém, que está mais perto da virtude. Realmente, o bom e o mau anseiam igualmente pela glória, pelas honras, pelo poder; aquele esforça-se por alcançá-los, mantendo-se no bom caminho, este, porque lhe faltam as boas qualidades, luta com as armas do engano e da mentira."

${ }^{14}$ Como frisamos, o conceito de uirtus que, segundo Earl, Salústio defende em sua obra é este: "the functioning of ingenium to achieve egregia facinora and thus to win gloria by the exercise of bonae artes" (EARL, 1961, p.16).
} 
correspondência atribuídos a Catilina pelo historiador, uma profunda oposição: nas cartas a que alude o capítulo 34 da obra, Catilina assume uma postura de humildade e até mesmo de arrependimento, ao afirmar sua intenção de partir para o exílio em Marselha, permitindo, assim, que a república fique em sossego; no entanto, na carta dirigida a Q. Catulo, tal intenção é totalmente desmentida, reforçando Catilina seu propósito de permanecer à testa da revolução, eufemisticamente designada por ele - como bem salienta Ernout em nota a essa passagem (SALLUSTE, 1980, p.88) - de "nouo consilio""15 (De C.C. $35,2)$.

Essa oposição - distinta das anteriormente analisadas, na medida em que não se trata de uma antítese apenas entre dois termos ou expressões, mas entre dois discursos - ratifica, de modo particular, dois dados apresentados no retrato de Catilina: de um lado, o fato de ser ele possuidor de um "animus [...] cuius rei lubet simulator ac dissimulator" 16 (De C.C. 5, 4); de outro, a idéia de que, desde que satisfaça seu desejo de apoderar-se da república, pouco se lhe dão os meios através dos quais isso será obtido (De C.C. 5, 6).

Analisados já um retrato e duas cartas, gostaríamos de nos deter agora no estudo da digressão sobre a história de Roma presente nos capítulos 6 a 13, o que nos permitirá aprofundar um pouco mais a questão das bonae artes - cujo exercício é o divisor de águas entre o bonus e o ignauus, ou, em outras palavras, entre o detentor da uirtus e aquele que não a possui.

A digressão propriamente dita começa no capítulo 6, mas não é supérfluo atentar para a forma como ela é introduzida no final do capítulo 5, ao expressar o autor o seu desejo de mostrar como Roma "paulatim immutata, ex pulcherruma <atque optuma> pessuma ac flagitiosissuma facta sit"17 (De C.C. 5, 9). A história de Roma passa a ser, a partir daqui, o grande sintagma que atualiza o par antitético passado x presente, a partir do qual se concretiza a oposição bonae artes x malae artes.

Antes de nos atermos especificamente a essa questão, julgamos pertinente referir outros pólos opositivos presentes na digressão em estudo, os quais ratificam o fato de ser o pensamento salustiano profundamente antitético.

Destacamos, em primeiro lugar, uma diferença existente entre os troianos e os aborígenes fundadores e primeiros habitantes de Roma: enquanto os primeiros estavam sob o comando de Enéias ("Aenea duce"), os outros eram homens que não tinham autoridades a guiá-los ("sine imperio") (De C.C. 6, 1).

Saliente-se, em seguida, uma retomada da antítese animus x corpus - enriquecida aqui pela presença de uma sinédoque, em que a parte (ingenium) vale pelo todo (animus) - quando o historiador se refere aos reis romanos, que tinham "corpus annis infirmum"18 mas "ingenium sapientia ualidum"19 (De C.C. 6, 6). Mais uma vez, reafirma-se a supremacia do intelecto sobre o corpo.

As antíteses significativas do ponto de vista da oposição passado x presente e, por conseguinte, da antítese bonae artes x malae artes passam a figurar, na digressão, a partir do capítulo 10, em cujo início encontramos um dos poucos empregos da adversativa sed com seu valor real - opositivo - e não meramente como um elemento de transição entre dois assuntos. Nesse ponto atinge o retrospecto aquele momento histórico que, para Salústio, é o grande marco que separa o passado, em que vigoravam as bonae artes, do presente, no qual o que prevalecem são os elementos negativos: a destruição de Cartago pelos romanos. Eis o que diz, a esse respeito, Earl: "Sallust is quite clear that the period in which uirtus reigned supreme at Rome was that before the destruction of Carthage, since which event Rome had been invaded by ambitio, auaritia and luxuria and there had been few of her citizens uirtute magnus" (EARL, 1961, p.11).

A partir desse momento, quando "cuncta maria terraeque patebant, saeuire fortuna ac miscere omnia coepit" ${ }^{20}$ (De C.C. 10, 1), as antíteses comportamentais tiveram seu início: "Qui labores, pericula, dubias atque asperas res facile tolerauerant, eis otium, diuitiae, optanda alias, oneri miseriaeque fuere" ${ }^{21}$ (De C.C. 10, 2).

É interessante salientar, nessas palavras, a oposição labor x otium, que, em termos paradigmáticos, se enquadra no dualismo metafísico, em que o valor é atribuído ao primeiro elemento.

\footnotetext{
15 “[...] decisão nova [...]."

16 "espírito [...] capaz de tudo fingir e dissimular [...]."

17 "[...] transformando-se paulatinamente, tornou-se da mais bela e melhor das repúblicas na pior e mais vergonhosa de todas."

18 "[...] o corpo alquebrado pelos anos [...]."

19 "[...] a mente enriquecida pela sabedoria [ ...]."

20 "[...] todos os mares e terras se abriam, eis a fortuna a se pôr em cólera e a tudo confundir."

21 "Aqueles que tinham, sem dificuldade, suportado fadigas, riscos e situações críticas e penosas, a esses a paz, as riquezas, coisas por sinal desejáveis, lhes serviram de peso e aflição."
} 
No entanto, ratificando mais uma vez que, em termos sintagmáticos, o elemento da segunda coluna não precisa ser de todo destituído de valor, ressalta Salústio que, em outras circunstâncias, o otium é um bem desejável. Nada mais natural que assim seja, uma vez que, como vimos no ensaio Considerações Preliminares sobre o Jogo Antitético na Historiografia de Salústio, é o otium que, concedendo ao historiador tempo para escrever, possibilita-lhe ser digno de glória idêntica àquela de que usufruem os que praticaram os feitos por ele narrados. Observamos, portanto, novamente que, no plano do discurso, Salústio deixa claro que cada elemento de um par antitético vale não por si mesmo, mas pelo uso que dele se faz. Essa constatação torna-nos partícipes da opinião de Earl de que, para o historiador, a uirtus está ligada à conduta do ser humano - ao uso que ele faz das bonae artes -, não sendo, primariamente pelo menos, um estado de espírito (EARL, 1961, p.11).

A centelha de todos os males que assolaram Roma a partir da destruição de Cartago, Salústio a coloca em duas ambições: "primo pecuniae, deinde imperi"22 (De C.C. 10, 3).

O desejo de dinheiro - auaritia - determinou o desaparecimento das boas qualidades do passado, substituindo-as por características presentes negativas:

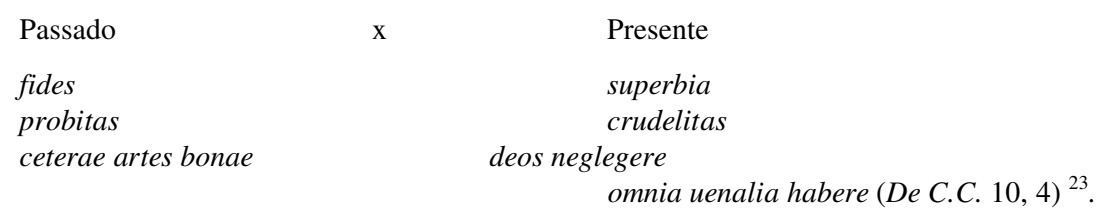

As qualidades que Salústio agrupa sob a expressão ceterae artes bonae são, segundo o capítulo 9 nos indica, as seguintes: concordia, ius bonumque (De C.C. 9, 1), magnificentia in suppliciis deorum, parcitas domi (De C.C. 9, 2), audacia in bello e aequitas ubi pax euenerat (De C.C. 9, 3) ${ }^{24}$.

Observe-se que, no eixo sintagmático, as antíteses não figuram através de pares tão rigidamente formados quanto no eixo paradigmático, no qual a um elemento da primeira coluna sempre correspondia outro na segunda. Agora, como ocorre com relação às cartas cujo teor é mencionado nos capítulos 34 e 35 e de que nos ocupamos um pouco antes, as oposições se configuram mais no plano do relato global do que através de termos antitéticos colocados lado a lado. Usando a terminologia de Lausberg, podemos afirmar que as "antíteses de palavras isoladas" (exclusivas no pólo paradigmático e nos primeiros capítulos do eixo sintagmático) são agora substituídas pelas "antíteses frásicas" (LAUSBERG, 1972, p.228-230).

Essa característica tende a reforçar-se, com a presença de um traço até então inédito na narrativa, no momento em que Salústio passa a tratar do segundo desejo que, aliado ao de dinheiro, constitui a origem de todos os males: o desejo de mando - ambitio. Nesse momento, o historiador nem chega a fazer referência explícita ao passado e às bonae artes, relatando diretamente os efeitos da ambitio no presente: "Ambitio multos mortalis falsos fieri subegit, aliud clausum in pectore, aliud in lingua promptum habere, amicitias inimicitiasque non ex re, sed ex commodo aestumare, magisque uoltum quam ingenium bonum habere" 25 (De C.C. 10, 5).

A oposição estabelece-se, assim, in absentia de um dos pólos antitéticos, o qual, no entanto, continua obviamente presente no nível semântico.

O final do capítulo 10 remete-nos, com um novo exemplo reforçativo da antítese passado $\mathrm{x}$ presente, à oposição, antes referida, que encerra o capítulo 5: "ciuitas inmutata, imperium ex iustissumo atque optumo crudele intolerandumque factum"26 (De C.C. 10, 6).

Além da auaritia e da ambitio, Salústio destaca ainda, nessa digressão sobre a história de Roma, um terceiro elemento negativo característico do presente - a luxuria. É de ressaltar que esse elemento não tem abrangência idêntica à dos dois primeiros. Enquanto a auaritia e a ambitio são relacionadas a todos os cidadãos, a luxuria aparece, pelo menos no início, especificamente ligada aos militares:

"Huc accedebat quod L. Sulla exercitum quem in Asia ductauerat, quo sibi fidum faceret, contra morem maiorum luxuriose nimisque liberaliter habuerat. Loca amoena, uoluptaria facile in otio

\footnotetext{
22 "[...] primeiro, a [...] do dinheiro, depois a do poder."

23 "Com efeito a cobiça deitou por terra a fidelidade, a honra e os demais valores; em seu lugar foi o orgulho, a crueldade, o desprezo dos deuses, a venalidade que ela nos ensinou."

${ }^{24}$ A concórdia, o direito e o bem, a generosidade nos sacrifícios aos deuses, a parcimônia em casa, a audácia na guerra, a eqüidade quando a paz retornava.

25 "A ambição levou [muit]os homens a se tornarem falsos, a ter escondida no coração uma coisa, ter outra bem visível na boca, a estimar as amizades e inimizades, não por si mesmas, mas pelas conveniências, a manter antes a aparência do que a alma boa."

26 "[...] a cidade se transformou, o mais justo e melhor dos governos se tornou o mais insuportável e cruel."
} 
ferocis militum animos molliuerant. Ibi primum insueuit exercitus populi Romani amare, potare, signa, tabulas pictas, uasa caelata mirari, ea priuatim et publice rapere, delubra spoliare, sacra profanaque omnia polluere. Igitur ei milites, postquam uictoriam adepti sunt, nihil relicui uictis fecere",27 (De C.C. 11, 5-7).

Impõem-se duas observações relativamente a essa ligação especial da luxuria aos soldados. A primeira delas diz respeito ao fato de a menor abrangência desse uitium não significar que ele seja menos pernicioso do que a auaritia e a ambitio - basta, para comprová-lo, que nos lembremos da enorme importância do exército no conjunto da sociedade romana. A segunda observação tem a ver com a função dessa referência à luxuria na elucidação de todos os dados envolvidos na antítese passado $\mathrm{x}$ presente: embora se encontrem, no próprio trecho acima transcrito, dados que nos permitem perceber essa oposição - como a expressão contra morem maiorum e o advérbio primum -, a verdade é que, num novo exemplo de antítese frásica, a inexistência da luxuria no passado já ficara explicitada no capítulo 7:

"Iam primus iuuentus, simul ac belli patiens erat, in castris per laborem usu militiam discebat, magisque in decoris armis et militaribus equis quam in scortis atque conuiuiis lubidinem habebant. Igitur talibus uiris non labor insolitus, non locus ullus asper aut arduus erat, non armatus hostis formidulosus; uirtus omnia domuerat. Sed gloriae maxumum certamen inter ipsos erat; se quisque hostem ferire, murum ascendere, conspici dum tale facinus faceret, properabat; eas diuitias, eam bonam famam magnamque nobilitatem putabant. Laudis auidi, pecuniae liberales erant; gloriam ingentem, diuitias honestas uolebant",28 (De C.C. 7, 4-6).

Repete-se, assim, o mito do paraíso perdido: Roma foi, no princípio, íntegra; corrompeu-se depois. Tal como na epopéia homérica, também em Salústio as gerações passadas foram melhores que as presentes:

"Operae pretium est, cum domos atque uillas cognoueris in urbium modum exaedificatas, uisere templa deorum quae nostri maiores, religiosissumi mortales, fecere. Verum illi delubra deorum pietate, domos suas gloria decorabant; neque uictis quicquam praeter iniuriae licentiam eripiebant. At hi contra, ignauissumi homines, per summum scelus omnia ea sociis adimere, quae fortissumi uiri uictores reliquerant: proinde quasi iniuriam facere, id demum esset imperio uti" 29 (De C.C. 12, 3-5).

Enfim, como conseqüência lógica da invasão de Roma pelas malae artes, tem-se que "multis tempestatibus haud sane quisquam Romae uirtute magnus fuit"30 (De C.C. 53, 5).

Essas palavras do historiador remetem-nos ao exame de outros dois momentos significativos da monografia salustiana: os discursos de César e de Catão, de um lado, e o retrato dos dois, do outro momentos esses que são intermediados por tais palavras.

Não obstante as suas diferenças de conteúdo (compondo uma expressiva antítese frásica), os discursos de César e de Catão são idênticos no que respeita ao paradigma que os sustenta, ou seja, a oposição passado (bom) x presente (mau): ambos os oradores vão buscar no passado exemplos que amparem as respectivas teses acerca da pena a ser imputada, no presente, aos conjurados.

César busca na atitude de Roma para com os ródios e os cartagineses o modelo para a sua proposta de não agir com excessivo rigor:

"Bello Macedonico, quod cum rege Perse gessimus, Rhodiorum ciuitas magna atque magnifica, quae populi Romani opibus creuerat, infida atque aduorsa nobis fuit. Sed postquam bello confecto de Rhodiis consultum est, maiores nostri, ne quis diuitiarum magis quam iniuriae causa bellum inceptum diceret, inpunitos eos dimisere. Item bellis Punicis omnibus, cum saepe

\footnotetext{
27 “Além do mais, Sila, para granjear a fidelidade do exército que comandava na Ásia, contrariando a tradição dos antepassados, habituara-o ao luxo e a uma disciplina indulgente demais. Lugares amenos e cheios de prazer não tardaram a amolecer no ócio o ânimo rude dos soldados. Foi aí que pela primeira vez o exército do povo romano se pôs a amar e a beber, a admirar estátuas, quadros, vasos cinzelados, a raptá-los de lugares públicos e privados, a saquear os templos, a nada respeitar, nem o sagrado nem o profano. Pois esses soldados, ao conquistar a vitória, nada deixavam aos vencidos."

28 "Primeiramente a juventude, assim que estava em condições de enfrentar as fadigas da guerra, aprendia nos quartéis arduamente o tirocínio militar e encontrava maior satisfação nas belas armas e nos cavalos de guerra do que nas mulheres e nos banquetes. Por isso, para tais homens a fadiga não era novidade, nenhum lugar era penoso e difícil, nenhum inimigo armado inspirava medo: o valor tinha superado todos os obstáculos. Entre eles era enorme a emulação pela glória: ferir o inimigo, escalar as muralhas, ser visto ao fazer tal façanha, para isso cada um porfiava. Estavam convencidos de que nisso estavam as verdadeiras riquezas, o verdadeiro prestígio e seu grande título de nobreza. Ávidos de louvores, generosos em matéria de dinheiro; eram seus anseios uma glória imensa, uma riqueza decente."

29 "Vale a pena, ao se conhecer casas e vilas construídas do tamanho de cidades, visitar os templos construídos pelos nossos antepassados, homens de grande religiosidade. Pois eles aos templos dos deuses decoravam com sua piedade, às casas, com a glória de suas façanhas, e dos vencidos nada tiravam senão a possibilidade de cometer injustiças. Os de hoje, ao contrário, homens de grande covardia, através dos maiores crimes, roubam dos aliados tudo que os vencedores, modelos de coragem, tinham lá deixado: como se, em fim de conta, o exercício do poder consistisse na prática da injustiça.”

30 "[...] por muito tempo em Roma realmente não houve nenhum homem de grande valor."
} 
Carthaginienses et in pace et per indutias multa nefaria facinora fecissent, numquam ipsi per occasionem talia fecere: magis quid se dignum foret quam quid in illos iure fieri posset quaerebant" $^{\text {"31 }}$ (De C.C. 51, 5-6).

Catão, por seu turno, propõe que se aplique aos conspiradores a pena capital, tomando como exemplo a atitude de Mânlio Torquato em relação ao próprio filho:

"Apud maiores nostros A. Manlius Torquatus bello Gallico filium suum, quod is contra imperium in hostem pugnauerat, necari iussit, atque ille egregius adulescens immoderatae fortitudinis morte poenas dedit; uos de crudelissumis parricidis quid statuatis cunctamini?"32 (De C.C. 52, 30-2).

A grande diferença que separa uma proposta da outra encontra sua justificativa no retrato, por contraste, que Salústio faz de César e de Catão no capítulo 54 e do qual destacamos os seguintes pares opositivos:

\section{César}

beneficiis ac munificentia

mansuetudine et misericordia

clarus factus

dando, subleuando, ignoscendo

miseris perfugium

facilitas

$\mathrm{x}$
magnus habetur
gloriam adeptus est
erat
laudabatur

Catão

integritate uitae seueritas dignitatem addiderat

nihil largiundo malis pernicies constantia (De C.C. 54$)^{33}$.

A antítese estabelecida entre os dois personagens reveste-se de uma característica que não pode ser ignorada: os traços distintivos apontados - a que se agregam outros em 54, 4-6 - não nos devem impedir de perceber, por trás deles, a estreita identidade que une César e Catão no sentido de serem dois representantes de uma classe quase em extinção na Roma da época: a dos homens uirtute magni.

Com efeito, se voltarmos a pensar na definição de uirtus antes apresentada, veremos que ambos preenchem as exigências por ela colocadas. Em primeiro lugar, observe-se que, segundo Salústio, eles são idênticos em "magnitudo animi" 34 (De C.C. 54, 1), o que nos permite inferir a espécie de ingenium de que são dotados; como afirma Earl, "animus, for Sallust, contains ingenium, and a man of magnitudo animi would clearly have ingenium bonum" (EARL, 1961, p.99). Em segundo lugar, salientem-se as bonae artes que caracterizam um e outro, as quais, não obstante distintas, são todas meios legítimos para atingir o mesmo fim, a gloria; uma vez mais nos reportamos a Earl, cuja análise acurada vem ao encontro do que pensamos:

"Of these 'qualities', pudor and abstinentia, ascribed to Cato, are elsewhere contrasted with audacia and largitio, which are described as malae artes. The inference is that pudor and abstinentia are bonae artes and with them nihil largiri. With Caesar's intention 'laborare, vigilare' may be compared labor, laborum patientia, industria, also bonae artes. His resolve to neglect his own business in attending to that of his friends may be considered as an example of fides, foundation of amicitia and again a Sallustian bona ars. It may be concluded that the other 'qualities' in this passage are likewise bonae artes" (EARL, 1961, p.100).

A parte final da comparação entre Catão e César mostra a forma distinta com que cada um deles prefere exercitar o seu ingenium bonum e as bonae artes que o caracterizam, com o fito de realizar egregia facinora. César "sibi magnum imperium, exercitum, bellum nouom exoptabat ubi uirtus enitescere posset" ${ }^{\prime 35}$ (De C.C. 54, 4); isso significa que, para ele, a consecução de egregia facinora, que lhe permitiria fazer com que sua uirtus se tornasse ainda mais notável e, por conseguinte, atingir mais

\footnotetext{
31 "Durante a guerra da Macedônia que fizemos contra o rei Perseu, a grande e poderosa nação dos ródios, que prosperara às custas dos recursos do povo romano, foi-nos desleal e hostil. No entanto, depois, ao término da guerra, quando se tratou de decidir sobre a sorte dos ródios, nossos antepassados, para que não se alegasse que a guerra tinha sido empreendida mais pelas riquezas do que pela injustiça, deixaram-nos ir sem punição. Igualmente, em todas as guerras púnicas, embora com freqüência os cartagineses, em tempo de paz e durante as tréguas, cometessem muitos crimes execráveis, jamais nossos antepassados, quando tiveram oportunidade, praticaram atos semelhantes: preocupavam-se mais em agir de acordo com sua dignidade do que em poder aplicar-lhes justos castigos."

32 "No tempo antigo, A. Mânlio Torquato, durante a guerra contra os gauleses, mandou matar seu filho, por ter ele, contra suas ordens, combatido contra o inimigo e esse jovem excepcional pagou com a morte sua coragem excessiva; vós, para decidir sobre a sorte de assassinos de extrema crueldade, vós hesitais?"

33 "César se distinguia pelos favores e generosidade, Catão pela vida inatacável. Aquele se tornou ilustre pela doçura e clemência, a este a severidade lhe conferia respeito. César granjeou a glória, dando, amparando, perdoando, Catão, sem nada prodigalizar. Um era o refúgio dos infelizes, o outro a desgraça dos maus. De César se louvava a afabilidade, de Catão, a firmeza.”

34 "[...] grandeza da alma [...]."

35 "....] para si ambicionava um grande império, um exército, uma guerra nada comum onde pudesse brilhar seu valor."
} 
gloria, estava estreitamente vinculada à prática militar. Quanto a Catão, "non diuitiis cum diuite neque factione cum factioso, sed cum strenuo uirtute, cum modesto pudore, cum innocente abstinentia certabat" 36 (De C.C. 54, 6); suas qualidades, portanto, destacam-se na vida civil; e são tantas que, "quo minus petebat gloriam, eo magis illum assequebatur" 37 (De C.C. 54, 6).

Dois homens "ingenti uirtute"38, não obstante "diuorsis moribus"39 (De C.C., 53, 6), César e Catão formam, se colocados lado a lado, uma antítese em relação a Catilina, que, dotado de ingenium malum prauumque e adepto das malae artes em lugar das bonae na realização de seus facinora, não pode ser considerado um homem portador de uirtus e, portanto, não faz jus à gloria que, em princípio e como todos os outros, aliás -, ambicionava.

\section{CONSIDERAÇÕES FINAIS}

Se pensarmos que, conforme diz Salústio, Catão e César correspondem à exceção em seu tempo, em que a regra são as condutas determinadas pela auaritia, pela ambitio e pela luxuria, Catilina pode muito bem ser considerado uma espécie de sinédoque: enquanto indivíduo, ele encarna todos os vícios de uma sociedade cuja história - mesmo que escrita carptim $^{40}$ (De C.C., 4, 2)- deve servir, especialmente através do contraste com a de um passado melhor, para que as gerações futuras saibam discernir quais as formas de conduta adequadas para alcançar a uirtus e, em conseqüência, para obter a gloria verdadeira, de que todos nós, seres humanos, deveríamos ser dignos.

\section{BIBLIOGRAFIA}

A CONJURAÇÃO de Catilina. In: TRATADO sobre a clemência / Sêneca; introdução, tradução e notas de Ingeborg Braren. A CONJURAÇÃO de Catilina; A guerra de Jugurta / Salústio; introdução e tradução de Antônio da Silveira Mendonça. Petrópolis, Vozes, 1990.

BARILLI, Renato. Retórica. Lisboa, Presença, 1979.

BARTHES, Roland. A retórica antiga. In: COHEN, Jean et alii. Pesquisas de retórica. Petrópolis, Vozes, 1975. S/Z. Paris, Seuil, 1970.

BAYET, Jean. Littérature latine. Paris, Armand Colin, 1965.

BESSELAAR, José Van den. Introdução aos estudos históricos. 2.ed. São Paulo, Herder, 1958.

BORNHEIM, Gerd A. Dialética: teoria, práxis. Ensaio para uma crítica da fundamentação ontológica da dialética. Porto Alegre, Globo, São Paulo, EDUSP, 1977.

CARDOSO, Zelia de Almeida. A literatura latina. Porto Alegre, Mercado Aberto, 1989.

EARL, D. C. The political thought of Sallust. Cambridge, University Press, 1961.

GOETTEMS, Míriam Barcellos. Considerações preliminares sobre o jogo antitético na historiografia de Salústio. Classica, Araraquara, supl. 2, p.117-123, 1993.

JAKOBSON, Roman. Lingüística e comunicação. São Paulo, Cultrix, 1969.

LAUSBERG, Heinrich. Elementos de retórica literária. 2.ed. Lisboa, Calouste Gulbenkian, 1972. Manual de retórica literaria. Fundamentos de una ciencia de la literatura. Madrid, Gredos, 1984. 2v.

MORA, José Ferrater. Diccionario de filosofía. 5.ed. Buenos Aires, Sudamericana, 1965. 2 v.

OTÁLORA, José Riquelme. Recursos léxicos y estilísticos del vocabulario salustiano en función del pragmatismo histórico. Revista Española de Lingüística, Madrid, v.2, p.297-317, 1978.

\footnotetext{
36 "Não pretendia concorrer em riqueza com o rico, [nem em mexericos com o mexeriqueiro, mas com o intrépido em coragem,] com o modesto em reserva, com o inocente em honestidade." Observação: o trecho entre colchetes, que falta na tradução do Prof. Antônio da Silveira Mendonça, foi por nós traduzido.

37 "[...] quanto menos procurava a glória, tanto mais ela o perseguia."

38 "[...] de extraordinário valor $[. .$.$] ."$

39 "[...] de temperamentos diferentes [...]."

${ }^{40} \mathrm{O}$ emprego do advérbio carptim por Salústio demonstra que ele não pretendeu escrever toda a história do povo romano, mas sim extrair dela alguns fatos (como a conjuração de Catilina, tema da obra em análise) - aqueles que lhe pareciam mais dignos de registro.
} 
PARZIALE, Mariano. Princípios de historiografia pragmática no proêmio do "Bellum Catilinarium" de Gaio Salústio Crispo. No prelo.

QUINTILIEN. Institution oratoire. Paris, Garnier, 1954. v.1.

RAMBAUD, M. Les prologues de Salluste et la démonstration morale dans son oeuvre. Révue des Études Latines, Paris, v.24, p.115-130,1947.

SALLUSTE. Catilina. Jugurtha. Fragments des Histoires. 12.tir. Texte établi et traduit par Alfred Ernout. Paris, Les Belles Lettres, 1980. 